\title{
A Prospective Study on Role of Cemented Total Hip Arthroplasty in Osteonecrosis of Hip Joint with Femoral Head Collapse in Elderly: A Study of 100 Cases
}

\author{
Dr. Anshul Dahuja, Dr.Gitanshu Dahuja, Dr.J.P.S.Walia
}

\begin{abstract}
Background: Avascular necrosis (AVN) head of femur is an extremely debilitating disease due to multifactorial etiology. We assessed the results of cemented total hip athroplasty in patients with idiopathic osteonecrosis of femoral head with collapse in elderly.

Material and methods: A prospective randomized controlled study conducted in 100 patients with idiopathic AVN of the hip joint in elderly were treated with cemented total hip arthroplasty with an average of 6.2 years. 5 Harris hip scoring system was used for the functional scoring of the patients. 6
\end{abstract}

\section{Introduction}

Arthroplasty is an operation to restore motion of a joint. It had its inception in the mid $19^{\text {th }}$ century. Since then surgeons have tried to give better function to a painful, damaged joint through the stages of extraarticular pseudoarthrosis, simple resection arthroplasty, interpositional arthroplasty, hemiarthroplasty and to the present era of total joint replacement. The goals of total hip arthroplasty are to relieve pain, to provide motion with stability and to correct deformity[1].

Total hip arthroplasty (THA) originally was indicated for the alleviation of incapacitating pain in patients older Than 65 years who could not be relieved sufficiently by non surgical means and for whom the only surgical alternative was resection of the hip joint (girdle stone resection arthroplasty)[2].

Conservative treatment frequently can decrease the severity of symptoms and restore some acceptable function. Only when pain, stiffness and deformity are persistent and progressive then more energetic treatment is required. There are many surgical options like arthrodesis, Mcmurray osteotomy, cup arthroplasty and total hip replacement. In modern era, total hip replacement is treatment modality of choice in advanced cases of osteoarthrosis of hip joint.[3]

Avascular necrosis (AVN) head of femur is an extremely debilitating disease due to multifactorial etiology occuring in relatively younger patients. It results in a collapse of necrotic segment leading to loss of congruence and subsequently degenerative arthritis of the hip joint. The most common presenting complaint is a deep throbbing pain in the groin associated with antalgic gait and limitation of movements of hip joint. Radiologically avascular necrosis appear as increased density of femoral head but the articular cartilage is preserved[4].

We assessed the results of cemented total hip athroplasty in patients with idiopathic osteonecrosis of femoral head with collapse.

Our aim was :

- To assess the clinical and functional improvement of the patient

- To restore early joint function of the hip joint and to assess the stability of the hip joint

- To assess complications of procedures if any and the survival of the prosthesis

\section{Method}

A prospective randomized controlled study conducted in 100 patients with idiopathic osteonecrosis of the hip joint in elderly were treated with cemented total hip arthroplasty for an average follow-up of 10.2 years. Only those patients were selected in whom all other common causes of osteonecrosis like steroid use, trauma, coagulation disorder etc. had been ruled out. A standard surgical technique using Southern, s approach was used by a single surgeon and Depuy or Ormed prosthesis was used depending upon the patients affordability and choice. [5]

Clinical and radiographic outcomes were assessed at a mean period of 10.2 years.

Harris hip scoring system was used for the functional scoring and the post operative radiographs were assessed by Gruen zones for the femoral component and DeLee and Charnley zones for the acetabular component. $[6,7,8]$ The formation of heterotopic ossification was graded according to the method described by Broker et al. [9]

Chemoprophylaxis is routinely carried out in all patients.

All surgeries were performed in conventional operation theatre. 
Numerous approaches to the hip joint have been described in the past century, each being claimed to have advantage over others. We have used Moore (southern) approach. Advantage of this approach is that it does not require routine osteotomy of greater trochanter and abduction function is not compromised.

We use only mechanical prophylaxis against DVT like calf pump, quadriceps contraction and hip squeeze etc. Pharmacoprophylaxis is used only in high risk cases.

\section{Results}

At the time of follow up, patient age varied from 48 to 78 years with a mean age of 61.5 years with mean follow-up of 10.2 years. 3 patients lost their follow-up.

Mean operative time performed for each case was $70 \mathrm{~min}$ (range 64-78 $\mathrm{min}$ ). The average amount of bleeding was $150 \mathrm{ml}(122 \mathrm{ml}-180 \mathrm{ml})$ inraoperatively and about $50 \mathrm{ml}(40 \mathrm{ml}-88 \mathrm{ml})$ in post operative drain.

Hospitalization was 8 days in an average range. At follow up average HHS was 87 (range 74-96). Radiolucent lines were observed in one acetabular and two femoral components, but no secondary interventions were performed as patients were asymptomatic.

Heterotropic ossification was observed in 3 patients with Brooker grade II.

One patient developed UTI which was successfully managed by catheter removal and proper antibiotic coverage and increased hydration.

One patient developed superficial wound infection which was managed successfully by conservative treatment.

One patient developed traumatic dislocation which was managed by closed reduction and traction for 6 weeks

We had one periprosthetic fracture which was treated with locking plate with unicortical screws and SS wiring. No case of DVT was reported in our study group.

\section{Discussion}

The short term results of cemented Total hip arthroplasty in patients with idiopathic osteonecrosis of the hip joint are encouraging. Cemented femoral component provides an immediate postoperative advantage (i.e. of intimate contact between the prosthesis cement and the bone, which permits dramatic early relief of pain and more weight - bearing). In contrast to some previous studies, in our study outcome of Total hip arthroplasty with cement in osteonecrosis hip has been excellent with use of new cementing techniques and implants.[7,10]

Improved poly-ethylene sterilization and storage and more recently cross linking have significantly reduced the wear and associated osteolysis and component loosening and failure.[10,11]

In Goetz et. al study, they found no femoral component loosening in cemented group whereas $25 \%$ in cementless group .In our study, 3 patients were reported with asymptomatic aseptic loosening after three years of follow up.[12]

Heterotropic ossification was present in 3 patients at follow up. Thomas et al have reported an incidence of heterotropic ossification in as many as $53 \%$ of cases. The low incidence in the present study could be due to minimum soft tissue dissection and non steroidal anti inflammatory drugs post operatively for 7-10 days and meticulous removal of cement particles and products of reaming from the soft tissue around the hip.[12,13]

Use of antibiotic prophylaxis was based on the studies in favour of the use of systemic antibiotic in orthopaedic surgery by Bryan et al.[14,15]

Wilson et al reported significant decrease in the infection rate when prophylactic antibiotic was used, from $11 \%$ to $1 \% .[14,15]$

Cementless implant is dependent on bone ingrowth and biological stabilization process which is slow in elderly patients as they have limited reserves. Young patients often have a small diaphyseal diameter which would require use of a smaller sized stem, if cementing, to accommodate adequate cement mantle. However, this is not the problem with the normal and wide femoral canal of the adult and elderly patients.[16]

Fat embolism has also been reported in literature in procedures in which cement was not used. In our study there was no case reported with fat embolism.[17,18,19]

The various techniques Total Hip Arthroplasty have evolved to improve cement fixation are low viscosity cement, centrifugation, vacuum mixing, medullary canal restrictors, porosity reduction, pressurization instruments, proximal PMMA coating of stem etc. Heavier, longer and stronger femoral components have been designed to avoid stem failure and to decrease stem in cement. At the same time smaller cross section stems of metals such as titanium with a lower modulus of elasticity Total Hip Arthroplasty may transfer greater stress to cement and bone are being tried.[19,20]

Young et al (1998) studied regarding patient factors pertinent to the outcome of total hip arthroplasty. They concluded that best functional outcome and prosthesis survival rate were among patients who were between 45 and 75 years of age, weight less than $70 \mathrm{~kg}$, had strong social support, had a higher educational level, had better preoperative functional status and had no co morbid disease.[21,22] 
Andrea et al (2006) performed a study to determine the status, at a minimum of twenty five years of a prospevtive single surgeon, series of patients treated with primary Charnley total hip arthroplasty with a contemporary femoral cementing technique that involves the use of a distal cement plug and a retrograde cement delivery system. Although it demonstrated the remarkable durability of the femoral fixation obtained with the polished flatback Charnley prosthesis and the contemporary cementing technique, there was some deterioration of the result with time. Inspite of these numerous modifications, aseptic loosening of components emerged as the single most still unsolved long term complication of cemented or cementless Total hip arthroplasty.[12 ]

Pre-operative planning to match patients and implants, restoration of hip center and biomechanics are important components. Similarly intraoperative attention to offset, leg length, component orientation, stability and motion without impingement are critical. The surgical expertise and experience affect the outcome of total hip arthroplasty. THA is a single dependable procedure in elderly patients whose general health and medical comorbidities preclude repeated operations.[22]

\section{Conclusion}

In the Indian subcontinent (developing countries), patients are poor and economic constraints are there. So, cemented THA is cost effective single stage procedure with good and acceptable results in long term followup. With continued technical advances, the longetivity of the implants will improve.

\section{References}

[1]. Turek SL. The Hip. In: Orthopaedic Principle and their Application. $4^{\text {th }}$ edn. Philadelphia: Lippincott - Raven Publishers; 2002. Vol.2.1124-33,1194-1200.

[2]. Berend ME, Thong AE, Faris GW et al. Total joint orthoplast in the exteremly elderly.

[3]. Aaron RK, Lennox D, Bounce GE et al. The conservative treatment of osteonecrosis of femoral head.

[4]. Bailey JP, Miller MI. Osteonecrosis of femoral head.

[5]. Osboren RP. The approach to the hip joint. Critical review. JBJS 18;49:1930-31.

[6]. Harris LJH. Extensive exposure of the hip joint. Clin Ortho. 91;58:1973.

[7]. Gruen TA, McNeic G<, Amstutz HC, Modes of failure of cemented stem type femoral components. A radiographic analysis of loosening. Clin orthop. 1979;141:17-27.

[8]. DeLee JG, Charnley J. Radiological demarcation of cemented sockets in total hip replacement. Clin Orthop 1976;121:20-32.

[9]. Brooker AF, Bowerman JW, Robinson RA, Riler LH Jr. Ectopic ossification following THR JBJS 1973;55A:1629-32.

[10]. GX Ni, WW Lu, KY Chiu. Cemented or uncemented femoral component in primary total hip replacement ? A review from a clinical and radiological perspective. Journal of orthopaedic surgery 2005;13(1):96-105

[11]. Saikko V, Calonius O, Keranen J . Wear of conventional and cross-linked ultra-high-molecular-weight polyethylene acetabular cups against polished and roughened CoCr femoral heads in a biaxial hip stimulator. J Biomed Mater Res 63(6):848-53,2002

[12]. Andrea E, Buckwalter BS, John J, Callaghan, Steve S. Liu, Douglas R. Pedersen, Devon D. Goetz et al. Results of Charnley Total hip arthroplasty with use of improved femoral cementing technique. JBJS 2006;88:1481-85

[13]. Thmpson R., Kane RL et al. Complications and short term outcomes associated with total hip arthroplasty. J arthroplasty. 17;32:2002.

[14]. Wilson PD, Agliettip, Salvatiea. Subacute sepsis of the hip treated by antibiotics and cemented prosthesis. JBJS 1974;56A:879

[15]. Bryan CS, Morgan SL. Cefazolinvs Cefamendole for prophylaxis during total hip replacement. ClinOrthop 1988;288

[16]. Canale ST. Arthroplasty of Hip. In: Campbell's Operative Orthopaedics. 10 $10^{\text {th }}$ edn. Philadelphia: Mosby Publishers; 2008. Vol.1, 346-351.

[17]. Christie J, Burnett R, Potts HR, and Pell AC. Echocardiography of transarterial embolism during cemented and uncemented hemiarthroplasty of the hip. JBJS Br 1994.76:409-12.

[18]. Pitto RP; Koessler M; and Draenert K: Prophylaxis of fat and bone marrow embolism in cemented total hip arthroplasty. ClinOrthop. 1998; 355:23-24.

[19]. Ries MD; Lynch F; Rauscher LA ; Richman J; Mick C and Gmez M. Pulmonary Function during and after total hip arthroplasty. Findings in patients who have insertion of a femoral component with and without cement. JBJS Am. 1993;75:581-7.

[20]. Ebramzadeh E, Sarmiento A et al. The cement mantle in total arthroplasty. JBJS. 1994.

[21]. Young NL, Chaeh D, Waddel JP, Wright JG. Patient chracteristics that affect the outcome of total hip arthroplasty: a review. Can J Surg 1998 Jun; 41 (3):184-85

[22]. 22 Katz J.N, Losina E., Barret., Phillips C.B, et al. Association between hospital and surgeon procedure volume and outcomes of total hip arthroplasty in united states medicare population. JBJS 2001; 83A:1662-9 

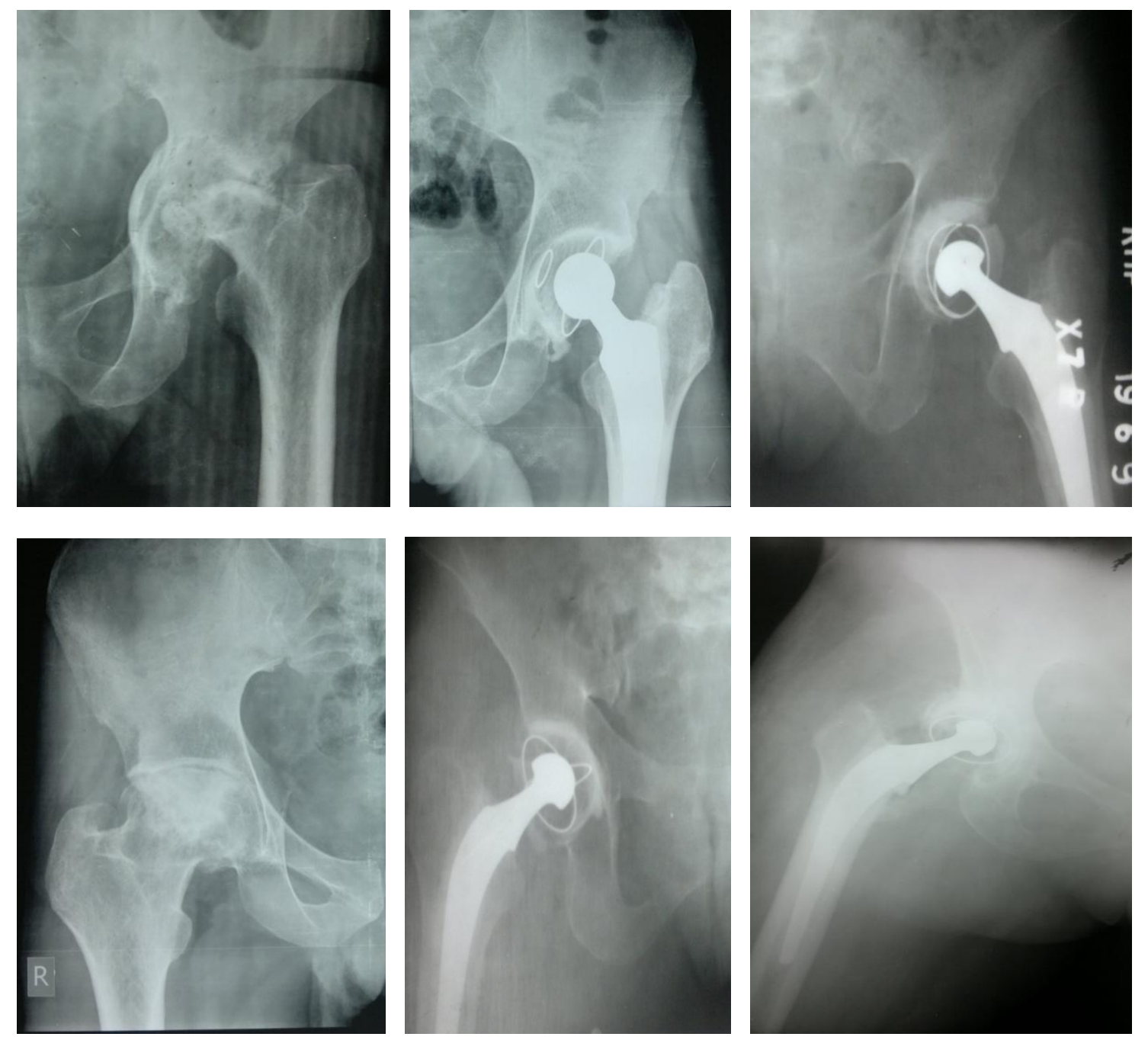

Pre-Op.

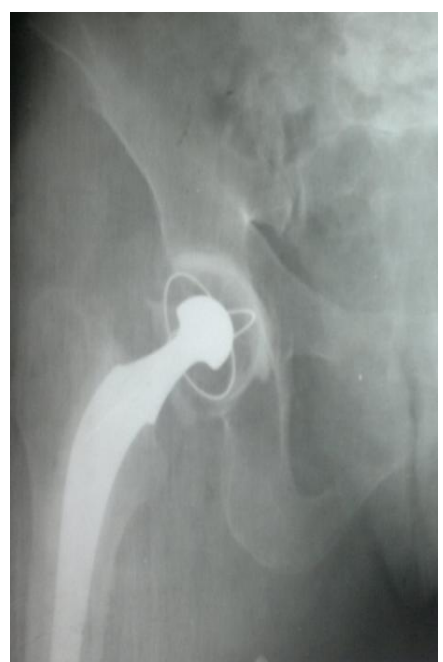

Post-Op. after 10 days

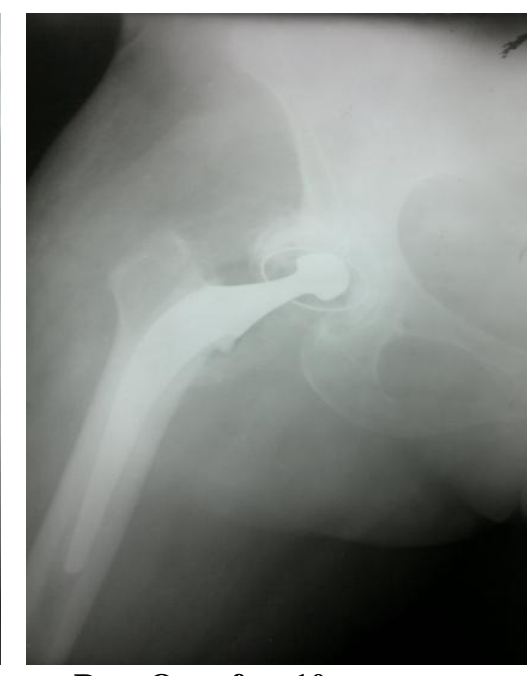

Post-Op. after 10 years

Fig. X-Rays showing THA in AVN hip 